\title{
A Modern Validation of Hotelling's Rule
}

\author{
Francis E. Raymond \\ Department of Economics and Finance, Rubel School of Business, Bellarmine University, Louisville, KY, USA \\ Email: fraymond@bellarmine.edu
}

How to cite this paper: Raymond, F.E. (2017) A Modern Validation of Hotelling's Rule. Theoretical Economics Letters, 7, 2070-2080.

https://doi.org/10.4236/tel.2017.77140

Received: September 18, 2017

Accepted: December 4, 2017

Published: December 8, 2017

Copyright $\odot 2017$ by author and Scientific Research Publishing Inc. This work is licensed under the Creative Commons Attribution International License (CC BY 4.0).

http://creativecommons.org/licenses/by/4.0/

(c) (i) Open Access

\begin{abstract}
In his seminal 1931 paper, Harold Hotelling demonstrates that in a competitive market for a nonrenewable resource, the price of the resource changes at a rate equal to the interest rate, or to the return on capital. This analysis augments and further justifies Hotelling's Rule by demonstrating that it holds within a multisector optimization model with human and physical capital, and with both renewable and non-renewable resources. When consumers and producers engage in optimizing behavior, on the margin the net return to physical capital equals the return to harvesting a renewable resource or extracting a nonrenewable resource. Moreover, this analysis reveals that the alleged inconsistencies of Hotelling's Rule with empirical findings are likely the result of market characteristics specific to each empirical study, not the foundational logic of Hotelling's rule.
\end{abstract}

\section{Keywords}

Endogenous Growth, Hotelling's Rule, Human Capital, Nonrenewable Resources, Renewable Resources

\section{Introduction}

This analysis demonstrates competitive criteria for market equilibrium when considering renewable or nonrenewable natural resources as factors of production in conjunction with an endogenously derived human capital component. Production depends upon choosing labor, physical capital, and the resource harvest rate in order to maximize intertemporal profits. As intertemporal utility maximizers, consumers choose both the rates of consumption and human capital accumulation. The consumer owns both the stock of physical capital and the resource stock. Thus, rent from physical capital and revenues from resource extraction are paid to the consumer. In turn, the consumer chooses consumption and time devoted to the accumulation of human capital so as to maximize inter- 
temporal utility. Specifically, human capital formation follows the rule postulated by Lucas [1]. A simultaneous solution to the consumer and producer problems yields a competitive multisector generalization of Hotelling's Rule [2]. This analysis is unique in that it combines a Lucasian endogenous learning component with a natural resource that serves as an input which can be interpreted as either renewable or renewable.

This analysis merges endogenous growth literature with that of both renewable and non-renewable resources. The conditions facing the producer and the consumer utilize the perfect foresight competitive approach of Becker [3], [4] with the dynamic methods of Tahvonen [5]. Technological advancement is represented by the joint accumulation of physical and human capital.

The literature describing the optimal extraction of nonrenewable resources is extensive (Krautkraemer [6]). Reacting to the energy crisis of the 1970s, earlier studies such as Solow [7], Dasgupta and Heal [8], Hartwick [9], Dixit, Hammond and Hoel [10], and Dasgupta and Mitra [11] focused primarily on the optimal extraction rate for a nonrenewable resource with exogenous technical progress. Several authors have acknowledged the correlation between growth and resource management. Specifically, Belratti, Chichilnisky and Heal [12] recognize the importance of endogenous growth when analyzing optimal resource extraction. Bretschger [13] describes various "substitution mechanisms" which lead to long run sustainable growth. Using more sophisticated mathematical techniques, Cass and Mitra [14] demonstrate the existence of a perpetual growth steady state under very specific conditions governing the development of technology and the substitutability of physical capital. In his analysis of nonrenewable resource use, Chichilnisky [15] focuses on specific preferences which implicitly define substitutability conditions without explicitly incorporating the dynamics of human capital accumulation. Ulph and Ulph [16] analyze the effect of learning on the optimal abatement of greenhouse gases, thus emphasizing the importance of information when determining optimal environmental policy. Finally, although Clark and Munro [17] and Clark, Clarke and Munro [18] analyze the optimal harvest rate of renewable resources, they do not consider how their optimal harvest rate might be affected if the resource were not a final good, but an input.

Finally, much has been made of the lack of empirical support for Hotelling's Rule. Krautkraemer [6] suggests that this is because the original specification of Hotelling's Rule does not capture technological advancements that lower extraction costs. Detractors cite empirical research indicating that the prices of non-renewable resources have not risen over time as one would expect with continued extraction (Barnett and Morse [19], Smith [20]). In particular, Cairn and Davis [21] offer a refutation of Hotelling's rule in an empirical study of gold prices. However, using the same data, Eisenhauer [22] demonstrates empirical results consistent with Hotelling's rule after employing more appropriate econometrics techniques.

Gaudet [23] analyzes US prices for oil, natural gas and a variety of minerals 
over impressively lengthy periods. Prices for these non-renewables are volatile. The author finds little evidence that Hotelling's rule is consistent given the variation in prices in these markets. To explain this, Gaudet claims that prices are influenced by several additional factors including extraction costs, market structure, the "durability of the resource" and uncertainty ([23], p.1043). In addition, each of these factors varies considerably among resource markets. In his conclusion, the author mentions additional factors he did not consider such as market failure that could also influence price in certain resource markets. Kronenberg [24] states that the failure of Hotelling's rule is due to the limitations of its assumptions. As evidence, he demonstrates that Hotelling's rule does not hold when there is a monopolistic supplier, but shows that the rule still holds within his framework when this condition is relaxed.

In a study of the application of Hotelling's rule to old growth timber, Livernois et al. [25] take care to design an empirical model that more accurately reflects characteristics specific to the old growth lumber market. Though imperfect, they find that this arguably more appropriately tailored model is roughly consistent with Hotelling's rule. They suggest that certain discrepancies should be expected due to short run volatility in general lumber prices and costs; "as the Hotelling rule predicts long run behavior of scarcity rents, the poor fit is perhaps to be expected ([25], p. 184)."

The reality is that Cairn and Davis, Gaudet, and Kronenberg address a fundamentally different issue. Rather than providing instances where Hotelling's rule fails, they are building upon the foundation that is Hotelling's rule in a manner that is very similar to the way in which researchers use pure competition as a reference point. Whereas these and other authors focus on a subset of exogenous factors which may exist in some markets at certain times, Hotelling's rule provides the foundation for the determination of non-renewable resource prices, ceteris paribus. Thus, the apparent inconsistency with empirical findings is the result of the original rule's simplicity and scope, not its logic. Similar to assumptions of perfect competition, Hotelling's rule serves as a foundational starting point for all subsequent discussions involving variations and characteristics specific to targeted non-renewable resource markets. In contrast, we ask a different question. Does Hotelling's rule hold in a multisector optimization model with both non-renewable and renewable resources? To this end, we create a model that both augments and further justifies Hotelling's Rule by demonstrating that it holds within a multisector optimization model with renewable and non-renewable resources, and human and physical capital.

\section{The Consumer Problem}

Define $N(t)=N_{o} \mathrm{e}^{n t}$ to represent the fully employed population at time $t$. In the spirit of Lucas [1], at each interval of time the $i^{t h}$ individual has the option to choose the proportion, $\mu_{t}^{i}$, of his productive time that he wishes to devote toward working in a productive capacity. The remaining time, $1-\mu_{t}^{i}$, is devoted 
to the development of human capital, $h_{t}$. Thus, $\dot{h}_{t}^{i}=\delta^{i} h_{t}^{i}\left(1-\mu_{t}^{i}\right)$, where the coefficient, $\delta^{i}$, indicates how efficiently an individual is able to develop his human capital.

Define effective labor as

$$
L_{t}=\int_{1}^{N(t)} \gamma_{t}(i) \mu_{t}(i) h_{t}(i) \mathrm{d} i
$$

where again, $\mu_{t}^{i}$ represents time devoted to working in a productive capacity, $h_{t}^{i}$ represents the skill level of the $i^{t h}$ individual at time $t$, and $\gamma^{i}$ is a coefficient indicating the ability of the $i^{\text {th }}$ individual to convert skill-hours into labor. We adopt Lucas' assumption that individuals possess identical skill levels, they choose their productive hours similarly, and $\delta=\delta^{i}$ and $\gamma=\gamma^{i}$ are constant. Thus, effective labor reduces to $L_{t}=N_{o} \mathrm{e}^{n t} \gamma \mu_{t} h_{t}=N_{t} \gamma \mu_{t} h_{t}$. In the spirit of Lucas, we assume that each consumer devotes the same proportion of time to work each period. Thus, $\mu_{i}=\mu$ and $L_{t}=N_{t} \gamma \mu h_{t}$ with $\mu$ determined endogenously.

These assumptions allow us to focus on a representative consumer. Let $C_{t}$ denote consumption of the capital-consumption good at time $t$. In each period the representative consumer receives benefits according to the utility function, $u\left(C_{t}, \mu\right):\left[\mathbb{R}^{+} \backslash(0,1]\right] \rightarrow \mathbb{R}^{+}$where $u \in C^{2}$ depends on personal consumption of the capital-consumption good and, the amount of time one chooses to devote to employment (or alternatively, the accumulation of human capital). We assume that $u_{C}>0$ and $u_{C C}<0$. According to the model the relationship between effective labor and work-time is $L_{t}>0 \Leftrightarrow \mu>0$. In addition, an increase in $\mu$ will increase consumer income. Thus, we assume that $u_{\mu}>0$ and $u_{\mu \mu}<0$. Assume the transversality condition, $\lim _{C \rightarrow 0^{+}} u_{C}=+\infty$, also holds.

The consumer receives the following stream of revenues from the firm,

$$
r_{t} K_{t}+q_{t} R_{t}+w_{t} L_{t}
$$

where $L_{t}$ is effective labor, $R_{t}$ is the resource extraction (harvest) rate and $K_{t}$ is physical capital. The prices associated with each of these inputs are, respectively, $w_{t}, q_{t}$ and $r_{t}$. In return, the consumer must compensate the firm for consumption and new units of physical capital. Physical capital depreciates at the rate, $\zeta$. Assuming that the consumption good and the physical capital good are the same, and that the price of that good is the numeraire $\left(p_{t} \equiv 1\right)$, this compensation amounts to

$$
C_{t}+\left(\dot{K}_{t}+\zeta K_{t}\right)=F\left(L_{t}, R_{t}, K_{t}\right)
$$

where production is defined by $Y_{t}=F\left(L_{t}, R_{t}, K_{t}\right)$ and $\dot{K}_{t}$ is investment in physical capital.

If consumption is discounted by $\mathrm{e}^{-\omega(t)}$ with $\omega>0$, the consumer's problem becomes,

$$
\max _{C, \mu} \int_{0}^{\infty} \mathrm{e}^{-\omega(t)} u\left(C_{t}, \mu\right) \mathrm{d} t
$$


subject to the budget constraint,

$$
r_{t} K_{t}+q_{t} R_{t}+w_{t} L_{t}=C_{t}+\left(\dot{K}_{t}+\zeta K_{t}\right)
$$

and the human capital constraint,

$$
\dot{h}_{t}=h_{t} \delta(1-\mu)
$$

In this optimal control problem the control variables are $C_{t}$ and $\mu$. The corresponding state variables are $K_{t}$ and $h_{t}$.

Proposition 1. Consumer optimization requires the net return to capital to equal the percentage change in effective labor,

$$
r_{t}-\zeta=n+\delta(1-\mu)
$$

Proof. The Hamiltonian associated with this problem is

$$
H=\mathrm{e}^{-\omega(t)}\left[u\left(C_{t}, \mu\right)\right]+\eta_{1}\left[r_{t} K_{t}+q_{t} R_{t}+w_{t} L_{t}-C_{t}-\dot{K}_{t}-\zeta K_{t}\right]+\eta_{2} h_{t} \delta(1-\mu)
$$

where $\eta_{1}$ and $\eta_{2}$ are the present value multipliers of this Hamiltonian system.

The first order conditions for a maximum are given by,

$$
\frac{\partial H}{\partial C}=\mathrm{e}^{-\omega(t)}\left[u^{\prime}\left(C_{t}, \mu\right)\right]-\eta_{1}=0 \text { and } \frac{\partial H}{\partial \mu}=\eta_{1} \gamma h_{t} N_{t}-\eta_{2} \delta h_{t}=0
$$

Thus,

$$
\eta_{1}=\mathrm{e}^{-\omega(t)}\left[u^{\prime}\left(C_{t}, \mu\right)\right]
$$

and

$$
\eta_{2}=\frac{\gamma N_{t}}{\delta} \mathrm{e}^{-\omega(t)}\left[u^{\prime}\left(C_{t}, \mu\right)\right]
$$

Next, differentiate Equations (2) and (3) with respect to time to obtain,

$$
\dot{\eta}_{1}=\mathrm{e}^{-\omega(t)}\left[(-\dot{\omega}) u^{\prime}\left(C_{t}, \mu\right)+u^{\prime \prime}\left(C_{t}, \mu\right) \dot{C}_{t}\right]
$$

and

$$
\dot{\eta}_{2}=\frac{\gamma N_{t}}{\delta} \mathrm{e}^{-\omega(t)}\left[(-\dot{\omega}+n) u^{\prime}\left(C_{t}, \mu\right)+u^{\prime \prime}\left(C_{t}, \mu\right) \dot{C}_{t}\right]
$$

Hence,

$$
\hat{\eta}_{1}=-\dot{\omega}+\frac{u^{\prime \prime}\left(C_{t}, \mu\right)}{u^{\prime}\left(C_{t}, \mu\right)} \dot{C}_{t}
$$

and

$$
\hat{\eta}_{2}=-\dot{\omega}+n+\frac{u^{\prime \prime}\left(C_{t}, \mu\right)}{u^{\prime}\left(C_{t}, \mu\right)} \dot{C}_{t}
$$

Next, find the costate equations. These are,

$$
-\frac{\partial H}{\partial K}=\dot{\eta}_{1}=-\eta_{1}\left(r_{t}-\zeta\right)
$$

and

$$
-\frac{\partial H}{\partial h}=\dot{\eta}_{2}=-\eta_{2} \delta(1-\mu)
$$


Note the costate equations,

$$
\hat{\eta}_{1}=-\left(r_{t}-\zeta\right)
$$

and

$$
\hat{\eta}_{2}=-\delta(1-\mu)
$$

Equating Equation (4) with (6), and (5) with (7), one sees,

$$
-\dot{\omega}+\frac{u^{\prime \prime}\left(C_{t}, \mu\right)}{u^{\prime}\left(C_{t}, \mu\right)} \dot{C}_{t}=-\left(r_{t}-\zeta\right)
$$

and

$$
-\dot{\omega}+\frac{u^{\prime \prime}\left(C_{t}, \mu\right)}{u^{\prime}\left(C_{t}, \mu\right)} \dot{C}_{t}=-(n+\delta(1-\mu))
$$

Equating (8) and (9), one obtains the necessary condition for consumer optimization (1).

\section{The Producer Problem}

We assume the producer is an intertemporal profit maximizer. This approach is quite common in both the continuous time models of capital accumulation and the renewable resource models, although this model differs from other renewable resource models in that the resource is a factor of production ${ }^{1}$.

The producer chooses the level of output and the resource extraction rate consistent with intertemporal profit maximization. Production, $Y_{t}=F\left(L_{t}, R_{t}, K_{t}\right)$, depends on effective labor, the resource extraction (harvest) rate and physical capital, again with prices $w_{t}, q_{t}$ and $r_{t}$. If discounting future profits depends on perfect knowledge of the stream of future interest rates such as,

$$
I(t)=\int_{0}^{t} i(\sigma) \mathrm{d} \sigma
$$

then the firm's problem is defined to be,

$$
\max _{R_{t}, Y_{t}} \int_{0}^{\infty} \mathrm{e}^{-I(t)}\left[F\left(L_{t}, R_{t}, K_{t}\right)-w_{t} L_{t}-q_{t} R_{t}-r_{t} K_{t}\right] \mathrm{d} t
$$

subject to two dynamic constraints,

$$
\begin{gathered}
\dot{K}_{t}=Y_{t}-C_{t}-\zeta K_{t} \\
\dot{X}_{t}=G\left(X_{t}\right)-R_{t}, \text { with } X_{t} \geq 0
\end{gathered}
$$

If $\Pi(t)=F\left(L_{t}, R_{t}, K_{t}\right)-w_{t} L_{t}-q_{t} R_{t}-r_{t} K_{t}$, the producer problem can be expressed as:

$$
\max _{R_{t}, Y_{t}} \int_{0}^{\infty} \mathrm{e}^{-I(t)} \Pi(t) \mathrm{d} t
$$

subject to Equations (10) and (11).

Since physical capital is also assumed to be the consumption good, consumers

${ }^{1}$ See Becker [3], Clark, Clarke, and Munro [18] and Clark and Munro [17]. Clark ([26], pp. 95-96) characterizes the optimal solution and derives an appropriate interest rate. 
purchase the new stock at the numeraire price. Effective labor and physical capital are fully employed. The firm hires labor at the going wage, rents all physical capital, and purchases the natural resource from consumers.

Proposition 2. Necessary conditions for intertemporal profit maximization are,

$$
F_{K}=r_{t}
$$

and

$$
i(t)=G^{\prime}\left(X_{t}\right)+\hat{\Pi}_{R}
$$

where $i(t)$ is the competitive interest rate in period, $t$.

Proof. Use the methods of optimal control to solve the producer problem. The present value Hamiltonian is,

$$
H=\mathrm{e}^{-\int_{0}^{t}(\sigma) \mathrm{d} \sigma}[\Pi(t)]+\lambda_{1}\left[Y_{t}-C_{t}-\zeta K_{t}\right]+\lambda_{2}\left[G\left(X_{t}\right)-R_{t}\right]
$$

The control variables for the producer problem are $R_{t}$ and $Y_{t}$. The corresponding state variables are $X_{t}$ and $K_{t}$. Thus, the first order conditions for the producer's problem are,

$$
\frac{\partial H}{\partial Y}=\lambda_{1}=0
$$

and

$$
\frac{\partial H}{\partial R}=\mathrm{e}^{-\int_{0}^{t_{0}}(\sigma) \mathrm{d} \sigma}\left[F_{R}-q_{t}\right]+\lambda_{1} F_{R}-\lambda_{2}=0
$$

Thus,

$$
\lambda_{1}=0
$$

and

$$
\lambda_{2}=\mathrm{e}^{-\int_{0}^{t_{i}(\sigma) \mathrm{d} \sigma}}\left[F_{R}-q_{t}\right]
$$

or,

$$
\lambda_{2}=\mathrm{e}^{-\int_{0}^{t} i(\sigma) \mathrm{d} \sigma} \Pi_{R}
$$

Differentiating these one sees that,

$$
\hat{\lambda}_{1}=0
$$

Also,

$$
\dot{\lambda}_{2}=\frac{\mathrm{d}\left[\mathrm{e}^{\left.-\int_{0}^{t_{i}(\sigma) \mathrm{d} \sigma}\right]}\right]}{\mathrm{d} t}\left[F_{R}-q_{t}\right]+\mathrm{e}^{-\int_{0}^{t_{0}(\sigma) \mathrm{d} \sigma}} \frac{\mathrm{d}\left[F_{R}-q_{\mathrm{t}}\right]}{\mathrm{d} t}
$$

so,

$$
\hat{\lambda}_{2}=-i(t)+\left[F_{R} \hat{-} q_{t}\right]
$$

or,

$$
\hat{\lambda}_{2}=-i(t)+\hat{\Pi}_{R}
$$


The first costate equation is,

$$
\dot{\lambda}_{1}=-\frac{\partial H}{\partial K}=-\mathrm{e}^{-\int_{0}^{t} i(\sigma) \mathrm{d} \sigma}\left[F_{K}-r_{t}\right]
$$

or,

$$
\dot{\lambda}_{1}=-\frac{\partial H}{\partial K}=-\mathrm{e}^{-\int_{0}^{t} i(\sigma) \mathrm{d} \sigma} \Pi_{K}
$$

The second costate equation is,

$$
\dot{\lambda}_{2}=-\frac{\partial H}{\partial X}=-\lambda_{2} G^{\prime}\left(X_{t}\right)
$$

or,

$$
\hat{\lambda}_{2}=-G^{\prime}\left(X_{t}\right)
$$

Combining Equations (14) and (16), and Equations (15) with (17), one obtains the necessary conditions for producer optimization,

$$
F_{K}=r_{t}
$$

and

$$
i(t)=G^{\prime}\left(X_{t}\right)+\hat{\Pi}_{R}^{2}
$$

Equation (13) represents the total return on natural resource use. In particular, $G^{\prime}\left(X_{t}\right)$ represents the own return to the resource. The term $\hat{\Pi}_{R}=\left[p_{t} F_{R}-q_{t}\right]$ is the percentage change in the marginal profit associated with natural resource use. Equation (13) is a generalization of the optimization condition derived by Clark [6]. In Clark's renewable resource model, the resource is not a factor of production. A single firm merely harvests and sells the resource. If the cost of harvesting the resource is zero, it follows that total profit is $q_{t} R_{t}$. Thus, the marginal rate of profit is $\hat{q}_{t}$, and Equation (13) reduces to Clark's efficiency condition, $i(t)=G^{\prime}\left(X_{t}\right)+\hat{q}_{t}$.

\section{A Generalization of Hotelling's Rule}

A competitive equilibrium is one in which the conditions satisfying the consumer problem (CP) and the producer problem (PP) coincide.

Theorem 1. A complete competitive solution requires that the net return to physical capital equal the rate at which effective labor is augmented, as well as the return to the natural resource:

$$
F_{K}-\zeta=n+\delta(1-\mu)=G^{\prime}\left(X_{t}\right)+\hat{\Pi}_{R}
$$

Proof. Combine Equations (8), (9), and (12) to obtain $F_{K}-\zeta=n+\delta(1-\mu)$. If one assumes perfect foresight, $i(t)=\dot{\omega}-\frac{u^{\prime \prime}\left(C_{t}, \mu\right)}{u^{\prime}\left(C_{t}, \mu\right)} \dot{C}_{t}{ }^{3}$. Equation (13) provides the right hand side of (18).

${ }^{2} \hat{x}_{t}=\frac{\dot{x}_{t}}{x_{t}}$ represents the percentage change in variable $x$ over time.

${ }^{3}$ Becker [4] demonstrates that this condition is a necessary condition for a perfect foresight competitive equilibrium. 
This analysis demonstrates a necessary condition for a competitive solution when a natural resource is an input and human capital accumulation is endogenous. The term $n+\delta(1-\mu)$ represents the development of effective labor (the sum of the rates of population growth and human capital accumulation). Therefore, Equation (18) states that, on the margin, the net return to physical capital must equal the rate at which effective labor is augmented (the sum of the rates of population growth and human capital accumulation), as well as the return to harvesting-or extracting-the natural resource. If the resource is nonrenewable $\left[G\left(X_{t}\right) \equiv 0\right]$, then in the absence of discounting, population growth, and human capital accumulation, Equation (18) reduces to $F_{K}=\hat{q}_{t}$. That is, the price of the resource varies according to the return to capital. Thus, this condition is an extension of Hotelling's Rule when resources are used as inputs.

This is where some mistakenly see a refutation of Hotelling's rule in industry specific cases. Hotelling's Rule is a generalization, but not inconsistent with industry specific examples. For example, Krautkraemer [6] states "Constant or falling nonrenewable resource prices are inconsistent with the basic Hotelling model...Exploration and discovery, or technological change that lowers extraction cost, can generate a decreasing resource price even as (the shadow price) is increasing ([6], p. 2078)." However, Equation (18) dictates that since $n+\delta(1-\mu)$ is positive, $G^{\prime}\left(X_{t}\right)+\hat{\Pi}_{R}>0$. If the resource is nonrenewable, $G^{\prime}\left(X_{t}\right)=0$, so $\hat{\Pi}_{R}=\left[F_{R} \hat{-} q_{t}\right]=\frac{\dot{F}_{R}-\dot{q}_{t}}{F_{R}-q_{t}}>0$. This condition is not violated by falling resource prices. In fact, according to this specification, one would expect falling resource prices whenever the marginal product of the resource is decreasing $\left(\dot{F}_{R}<0\right)$.

\section{Conclusions}

Harold Hotelling [2] demonstrated that in a competitive market for a nonrenewable resource, the price of the resource changes at a rate equal to the interest rate, or the return on capital. Empirical studies that claim to refute Hotelling's rule focus on market-specific characteristics found only in some resource markets at certain times. In contrast, Hotelling's rule provides the foundation for the determination of non-renewable resource prices, ceteris paribus. Hotelling's rule reveals the logic driving resource prices in the long-run. Empirical studies critical of the rule are in fact sector specific modifications of Hotelling's rule. Hotelling himself demonstrates how different levels of competition leads to variations in the original rule [2]. More carefully constructed studies reveal this through more appropriately refined models that reveal Hotelling's rule once industry specific characteristics are relaxed.

In contrast, this study answers a significantly different question. Does Hotelling's rule hold in a multisector optimization model with both non-renewable and renewable resources? In doing so, we augment and further justify Hotelling's Rule within a multisector optimization model with human and physical capital, and with both renewable and non-renewable resources. Within this 
framework, a competitive solution requires the net return to physical capital equal (1) the rate at which effective labor increases and (2) the return to the renewable or non-renewable resource. Moreover, a simpler version of the model yields results that are consistent with Hotelling's original rule.

\section{References}

[1] Lucas, R.E. (1988) On the Mechanics of Economic Growth. Journal of Monetary Economics, 22, 3-42. https://doi.org/10.1016/0304-3932(88)90168-7

[2] Hotelling, H. (1931) The Economics of Exhaustible Resources. Journal of Political Economy, 39, 137-175. https://doi.org/10.1086/254195

[3] Becker, R.A. (1981) The Duality of a Dynamic Model of Equilibrium and an Optimal Growth Model: The Heterogeneous Capital Goods Case. The Quarterly Journal of Economics, 2, 271-300. https://doi.org/10.2307/1882391

[4] Becker, R.A. (1982) The Equivalence of a Fisher Competitive Equilibrium and a Perfect Foresight Competitive Equilibrium in a Multi-Sectoral Model of Capital Accumulation. International Economic Review, 23, 19-34. https://doi.org/10.2307/2526460

[5] Tahvonen, O. (1991) On the Dynamics of Renewable Resource Harvesting and Pollution Control. Environmental and Resource Economics, 1, 97-117.

[6] Krautkraemer, J.A. (1998) Nonrenewable Resource Scarcity. Journal of Economic Literature, 36, 2065-2107.

[7] Solow, R.M. (1956) A Contribution to the Theory of Economic Growth. Quarterly Journal of Economics, 32, 65-94. https://doi.org/10.2307/1884513

[8] Dasgupta, P. and Heal, G. (1974) The Optimal Depletion of Exhaustible Resources. Review of Economic Studies, Symposium Issue, 41, 3-28. https://doi.org/10.2307/2296369

[9] Hartwick, J.M. (1977) Intergenerational Equity and the Investing of Rents from Exhaustible Resources. American Economic Review, 67, 972-974.

[10] Dixit, A., Hammond, P. and Hoel, M. (1980) On Hartwick's Rule for Regular Maximin Paths of Capital Accumulation and Resource Depletion. Review of Economic Studies, 47, 551-556. https://doi.org/10.2307/2297306

[11] Dasgupta, P. and Mitra, T. (1983) Intergenerational Equity and Efficient Allocation of Exhaustible Resources. International Economic Review, 24, 133-153. https://doi.org/10.2307/2526119

[12] Beltratti, A., Chichilnisky, G. and Heal, G. (1995) Existence of an Optimum Growth Path with Endogenous Technical Change. Economics Letters, 48, 433-439. https://doi.org/10.1016/0165-1765(94)00594-R

[13] Bretschger, B. (1998) How to Substitute in Order to sustain: Knowledge Driven Growth under Environmental Restrictions. Environment and Development Economics, 3, 425-442. https://doi.org/10.1017/S1355770X98000229

[14] Cass, D. and Mitra, T. (1991) Indefinitely Sustained Consumption Despite Exhaustible Natural Resources. Economic Theory, 1, 119-146. https://doi.org/10.1007/BF01211530

[15] Chichilnisky, G. (1997) What is Sustainable Development? Land Economics, 73, 467-491. https://doi.org/10.2307/3147240

[16] Ulph, A. and Ulph, D. (1997) Global Warming, Irreversibility and Learning. The Economic Journal, 107, 636-650. 
https://doi.org/10.1111/j.1468-0297.1997.tb00031.x

[17] Clark, C.W. and Munro, G.R. (1975) The Economics of Fishing and Modern Capital Theory: A Simplified Approach. Journal of Environmental Economics and Management, 2, 92-106. https://doi.org/10.1016/0095-0696(75)90002-9

[18] Clark, C.W., Clarke F.H. and Munro, G.R. (1979) The Optimal Exploitation of Renewable Resource Stocks: Problems of Irreversible Investment. Econometrica, 47, 25-47. https://doi.org/10.2307/1912344

[19] Barnett, H.J. and Morse, C. (1963) Scarcity and Growth: The Economics of Natural Resource Availability. Resources for the Future. Johns Hopkins University Press, Baltimore.

[20] Smith, V.K. (1981) The Empirical Relevance of Hotelling's Model for Natural Resources. Resources and Energy, 3, 105-117. https://doi.org/10.1016/0165-0572(81)90018-9

[21] Cairns, R.D. and Davis, G.A. (1998) On Using Current Information to Value Hard-Rock Mineral Properties. Review of Economics and Statistics, 80, 658-663. https://doi.org/10.1162/003465398557744

[22] Eisenhauer, J.G. (2005) A Test of Hotelling's Valuation Principle for Nonrenewable Resources. Empirical Economics, 30, 465-471. https://doi.org/10.1007/s00181-005-0242-Z

[23] Gaudet, G. (2007) Natural Resource Economics under the Rule of Hotelling. Canadian Journal of Economics/ Revue Canadienne d Economique, 40, 1033-1059. https://doi.org/10.1111/j.1365-2966.2007.00441.x

[24] Kronenberg, T. (2008) Should We Worry about the Failure of the Hotelling Rule? Journal of Economic Surveys, 22, 774-793. https://doi.org/10.1111/j.1467-6419.2008.00549.x

[25] Livernois, J., Thille, H. and Zhang, X. (2006) A Test of the Hotelling Rule using Old Growth Timber Data. Canadian Journal of Economics/Revue Canadienne d Economique, 39, 163-186. https://doi.org/10.1111/j.0008-4085.2006.00343.x

[26] Clark, C.W. (1990) Mathematical Bioeconomics: The Optimal Management of Renewable Resources. 2nd Edition, Wiley, New York. 